\title{
Clinical and metabolic effects of the original io- dine metabolic composition in the experiment on calves
}

\author{
A. A. Evglevskiy ${ }^{1}$, O.M. Shvets ${ }^{2, *}$, and T.I. Mikhaleva ${ }^{2}$ \\ ${ }^{1}$ Kursk Federal Agrarian Scientific Center', Russia \\ ${ }^{2}$ Kursk State Agricultural Academy named after I.I. Ivanov, Russia
}

\begin{abstract}
The article provides a theoretical justification for the development of a complex iodine metabolic composition based on an iodinepolymer complex (iodinol) and succinic acid. The research on the effectiveness of the proposed composition for the correction of energymetabolic disorders in calves with severe iodine deficiency was carried out. The objects of research were calves with clinical signs of iodine deficiency and pronounced energy metabolic disorders. During the experiment, it was found that the test calves showed a marked improvement in the clinical condition. The thyroid status normalized, the total protein and glucose indicators approached the physiological norm, and the reserve alkalinity of the blood increased. The energetic metabolic effect was due to the combined action of iodinol and succinic acid. The obtained results indicate the opening prospect of an injection method for the use of an iodine polymer complex based on iodine-iodide with polyvinyl alcohol (iodinol) in combination with sodium succinate, not only as an effective approach to cupping and eliminating the iodine deficiency symptoms, but also as an active energy-metabolic drug with a potentially high anti-infective activity.
\end{abstract}

\section{Introduction}

One of the global and vital problems of mankind is iodine deficiency. 'SOS for humanity' that is the name given by the World Health Organization experts to the problem of iodine deficiency. Iodine deficiency diseases are the most common non-infectious pathology in the world [1,2].

Animals, especially farm animals, are as sensitive to iodine deficiency as humans.

If iodine deficiency is present in the body of animals, the biosynthesis of thyroid hormones is disrupted, which leads to a decrease in the intensity of redox processes, and as a result all types of metabolism: protein, fat, carbohydrate, macro- and microelement, as well as energy metabolism are disrupted. Failure of the thyroid gland is accompanied by the development of severe pathobiochemical processes, which leads to the clinical manifestation of pathophysiological conditions.

\footnotetext{
* Corresponding author: oshvec@yandex.ru
} 
In cows, iodine deficiency is most often manifested by articular pathology with the development of arthritis and arthrosis, pathology of pregnancy and impaired reproductive function $[3,4,5]$. The issues of prevention of iodine deficiency conditions are economically significant for industrial animal husbandry [5]. In countries experiencing natural iodine deficiency, government programs have been developed that provide for the use of iodinecontaining supplements in the diets of productive animals [6-11].

Despite the fact that the simplest and most affordable way to eliminate iodine deficiency in the body is to include iodized salt in the diet, nevertheless, for a number of reasons, this method cannot be of choice, especially in practical veterinary medicine. First of all, the feed method of using biologically active additives excludes the possibility of dosed individual therapeutic or preventive treatment. Besides, the iodine concentration in iodized salt is unstable and decreases significantly during storage, to the extent of complete loss [4].

In this regard, the use of iodized salt alone, when added to feed or as part of premixes, cannot be considered an effective approach. In addition, inorganic iodine compounds (potassium iodide or sodium) are transformed into forms indigestible for the body, or, accumulating in large quantities in the thyroid gland, have a toxic effect on thyrocytes. A more rational approach to the prevention of diseases associated with iodine deficiency, including ensuring appropriate regulation of metabolic processes in the body, may be the use of organic forms of iodine or chelated compounds [12,13].

It is this circumstance that was taken into account when determining the author's exploratory studies in the development of a complex iodine-metabolic composition suitable for parenteral administration.

\section{Research objective}

Theoretical and experimental substantiation of the development of a complex iodine metabolic composition based on an iodine polymer complex and succinic acid for correction of energy metabolic disorders in conditions of severe iodine deficiency.

Iodinol was used as an iodine polymer complex. The iodinol preparation is an aqueous solution consisting of iodine (0.1\%), potassium iodide ( $0.9 \%)$, and polyvinyl alcohol [14].

The first large-scale use of an iodinated solution, which later served as basis for the development of iodinol medication, took place in 1941. The medication called 'blue' iodine was used under extreme conditions $[13,15]$. The clinical efficacy of 'blue' iodine was so high that the clinical symptoms of dysentery stopped even in seriously ill patients on the 3rd-4th day [15]. Since then, a huge clinical experience has been accumulated in the use of iodinol in medicine and veterinary medicine. Iodinol, in contrast to elemental iodine, has low toxicity, has antiviral, antimicrobial and antifungal activity [14].

The unique spectrum of the metabolic action of succinic acid predetermined the possibility of its use as a metabolic component. Numerous experimental studies carried out by Kondrashova M.N. back in the 70s at the Institute of Biophysics of the Russian Academy of Sciences showed that exogenous use of succinic acid, even at extremely low dosages, provides an exceptionally high metabolic effect [20].

Currently, succinic acid is a universal component widely used to improve the pharmacological activity of drugs [16-19].

The inclusion of iodinol or sodium succinate with a similar concentration in the composition made it possible to obtain a composition with a pronounced energy-metabolic activity $[21,22]$. 


\section{Material and research methods}

A prototype of iodinol in combination with sodium succinate [21] and pharmacopoeial iodinol were used as test medications. Method of application - injection (intramuscularly).

The objects for clinical trials were calves with clinically pronounced signs of iodine deficiency. Three groups of calves were formed (two experimental groups and one control group, 10 heads in each). The iodine metabolic composition was tested on the first experimental group and the pharmacopean iodinol was tested on the animals of the second experimental group.

The tested medications were injected intramuscularly in a volume of $2.5 \mathrm{ml}(20,000 \mu \mathrm{g}$ of iodine). Considering the serious clinical status of the calves, the medications were administered three times, once every 7 days.

The control over the state of health of the experimental animals was carried out by means of clinical observations and comparison of biochemical parameters with the control group.

The biochemical studies were carried out using Eos Bravo forte automatic analyzer (Hospitex Diagnostics, Italia) with Abris diagnostic kits (Russia).

The determination of thyroid hormones, thyroxine and triiodothyronine, in the blood serum was carried out by the method of enzyme-linked immunosorbent assay on an automatic Teacan Sunrise analyzer.

\section{Research results and their discussion}

The initial clinical status of the calves - delay in growth and development, impaired growth of the hair coat, its peculiar curliness and rumpleness, head and body alopecia, dermatitis with predominant localization in the distal part of the extremities. All the selected calves showed signs of myxedema (submandibular edema).

The observed clinical forms of abnormalities are most typical for hypomicroelementosis, iodine and vitamin deficiencies, which were confirmed by the results of biochemical studies of the blood serum of calves with clinical abnormalities.

Such calves were found to have extremely low background indices of reserve alkalinity - 24.3-25.6 vol\% $\mathrm{CO}_{2}$ (metabolic acidosis), glucose levels-1.2-1.4 (energy deficit), hemoglobin-73.4-76.0 g/l (anemic syndrome), copper, zinc, cobalt (hypomicroelementosis), traces of carotene (vitamin deficiency), protein - 62.3-63.4 g/l (hypoproteinemia).

The level of thyroid hormones was significantly reduced. Thus, the content of T3 (triiodothyronine) did not exceed $0.75 \mathrm{nmol} / \mathrm{l}$, and the thyroxine level amounted to $11.2-11.7$ $\mathrm{nmol} / \mathrm{l}$, which is significantly lower than normal and, in combination with clinical signs, indicates iodine deficiency.

During the experiment, the dynamics of the hormonal status of calves was studied. The data obtained are presented in the diagrams. 


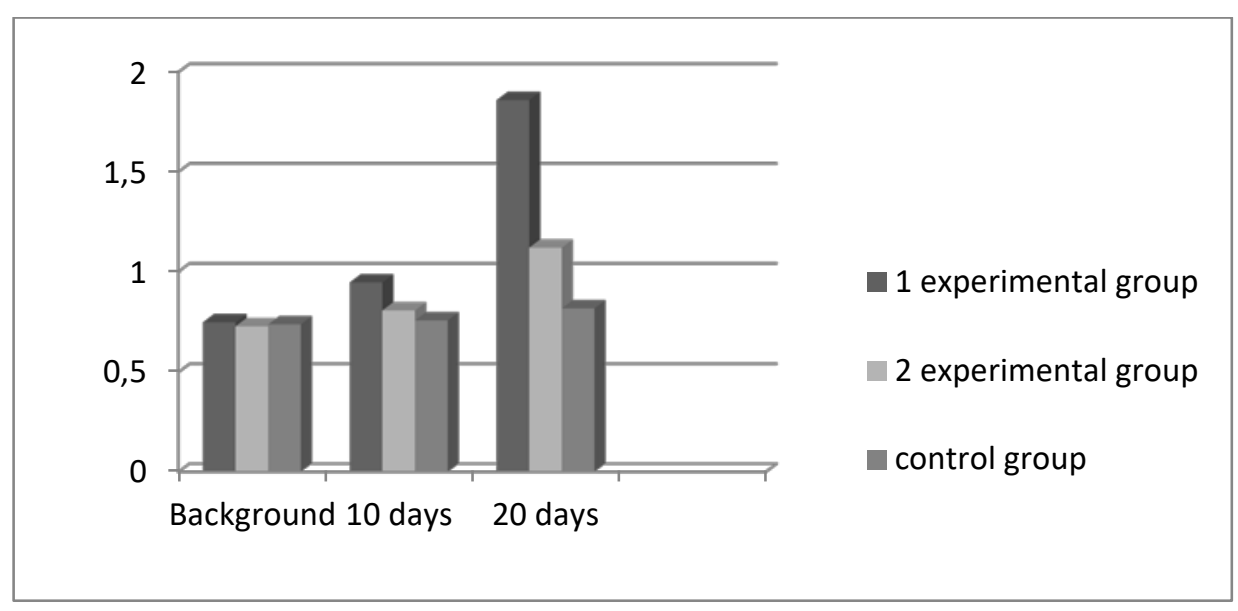

Fig. 1. Dynamics of the triiodothyronine level (nmol/l) in the blood of calves

From the data presented in Figure 1, it can be seen that the level of triiodothyronine significantly increased $(p<0.05)$ in the calves of the first experimental group, approaching the physiological norm. The hormone level in the blood of calves of the second experimental group did not increase significantly, and in the control group it remained practically at the same level.

Figure 2 shows the dynamics of the thyroxine level in the blood of calves from the experimental and control groups.

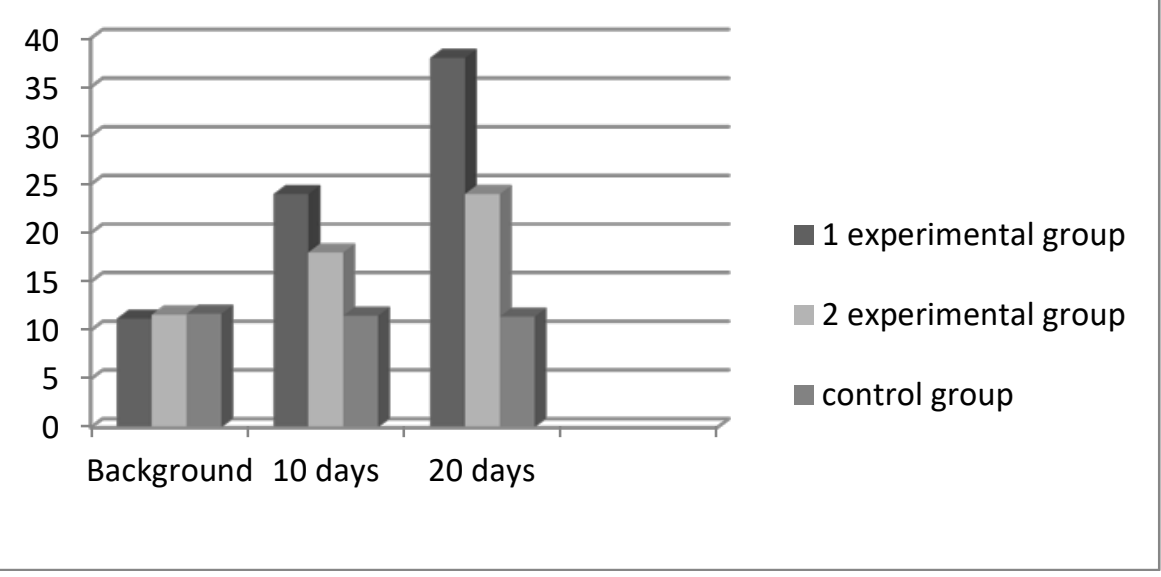

Fig. 2. Dynamics of thyroxine level (nmol/l) in the blood of calves

The thyroxine level in the first experimental group of calves increased significantly $(\mathrm{p}<0.05)$. The increase was less pronounced in the second experimental group, and in the control group there was a slight decrease in the thyroxine level in comparison with the background values.

Significant changes were noted in biochemical parameters (Table 1). 
Table 1. Dynamics of hematological and biochemical parameters

\begin{tabular}{|l|c|c|c|c|}
\hline Study period & $\begin{array}{c}\text { Hemoglobin, } \\
\mathrm{g} / \mathrm{l}\end{array}$ & $\begin{array}{c}\text { Total pro- } \\
\text { tein, g/l }\end{array}$ & $\begin{array}{c}\text { Glucose, } \\
\text { mmol/l }\end{array}$ & $\begin{array}{c}\text { Reserve alka- } \\
\text { linity, vol.\% } \\
\mathrm{CO}_{2} \leq\end{array}$ \\
\hline Norm & $110-120$ & $72-86$ & $2.2-3.3$ & $46-66$ \\
\hline \multicolumn{5}{|c|}{1 experimental group } \\
\hline Background & $73.4 \pm 1.3$ & $62.3 \pm 2.1$ & $1.6 \pm 0.01$ & $25.6 \pm 0.56$ \\
\hline 10 days & $83.5 \pm 2.4$ & $69.3 \pm 2.5$ & $2.1 \pm 0.01$ & $38.1 \pm 1.04$ \\
\hline 20 days & $102.3 \pm 4.3$ & $71.3 \pm 2.6$ & $2.3 \pm 0.02$ & $42.5 \pm 1.64$ \\
\hline \multicolumn{5}{|c|}{2 experimental group } \\
\hline Background & $76.0 \pm 1.8$ & $63.4 \pm 2.1$ & $1.6 \pm 0.01$ & $24.3 \pm 0.46$ \\
\hline 10 days & $80.5 \pm 2.2$ & $69.3 \pm 2.5$ & $1.8 \pm 0.02$ & $28.1 \pm 1.04$ \\
\hline 20 days & $82.3 \pm 3.2$ & $71.3 \pm 2.6$ & $1.9 \pm 0.01$ & $36.5 \pm 1.64$ \\
\hline \multicolumn{5}{|c|}{ Control group } \\
\hline Background & $77.2 \pm 1.6$ & $63.3 \pm 2.4$ & $1.5 \pm 0.04$ & $25.2 \pm 0.46$ \\
\hline 10 days & $75.3 \pm 2.1$ & $69.3 \pm 2.5$ & $1.6 \pm 0.02$ & $25.7 \pm 1.12$ \\
\hline 20 days & $75.5 \pm 3.0$ & $71.3 \pm 2.6$ & $1.6 \pm 0.05$ & $26.5 \pm 1.52$ \\
\hline
\end{tabular}

In the course of clinical observations, it was found that pronounced changes in the experimental calves of the first group appeared after one day. At first, this was manifested only by an improvement in appetite. On the 17-20th day, the calves that were tasted with the iodine metabolic composition showed hair growth in areas with alopecia and an improvement in the hair coat. Myxedema symptoms were reduced. However, the clinical effect of reducing dermatological lesions was insufficient. The reason for the deficiency was an unresolved deficiency of trace elements of iron, copper, cobalt, and zinc.

In the first experimental group, the indicators of total protein and glucose approached the physiological norm. This effect is associated with the high ability of succinic acid to activate energy metabolism in conditions of hypoxia (anemic syndrome). The reserve alkalinity of the blood increased significantly, which indicates metabolic acidosis correction.

The fact is that succinic acid has the ability to activate the involvement of the most problematic substrates in energy metabolism, such as lactate and keto acids [23-25]. Besides, sodium hydroxide is formed in the course of metabolic transformations of succinic acid or its succinate salts. It is sodium hydroxide that deacidifies the body [25].

One of the most valuable properties of succinic acid is its ability to enhance the utilization of lactic acid, which is capable of being absorbed in the liver, kidneys and intestines with the formation of glucose and its further oxidation [25,26]. This is the energetic and metabolic effect of succinic acid. Iodine, no matter how useful, does not have energetic activity. However, such activity is possessed by succinic acid. In the body, only succinic acid, and not other substrates of the Krebs cycle oxidation, monopolizes the respiratory chain. Thus, this is a real approach to activating the aerobic, the most productive way of energy production.

The fact is that the aerobic way of energy synthesis is 18 times higher than the anaerobic one, therefore, the introduction of succinic acid is more effective than infusion with glucose.

This is the energetic and metabolic effect of succinic acid.

\section{Conclusion}

Thus, at this stage of clinical trials, there is every reason to believe that the injection of an iodine polymer complex based on iodine-iodide with polyvinyl alcohol in combination with sodium succinate provided a fairly effective normalization of pathobiochemical processes (metabolic effect), a pronounced activation of energy metabolism (energy effect), and, in 
general, an energy-metabolic effect. Positive effect was achieved with clinically pronounced iodine deficiency.

The results obtained indicate the opening prospect of an injection method of using an iodine polymer complex based on iodine-iodide with polyvinyl alcohol in combination with sodium succinate not only as an effective approach to relieve and eliminate the symptoms of iodine deficiency, but also as an active energetic metabolic medication with a potentially high anti-infective activity.

\section{References}

1. Platonova N.M. Iodine deficiency: current state of the problem. Klinicheskaya i eksperimental'naya tireoidologiya [Clinical and experimental thyroidology], 2015, vol. 11, No. 1, pp. 12-20.

2. Platonova N.M. Yoddefitsitnye zabolevaniya (profilaktika, diagnostika, lechenie i monitoring) [Iodine deficiency diseases (prevention, diagnosis, treatment and monitoring)]. Diss. abstract for MD. Moscow, 2010.

3. Manukalo S.A., Shantyz A.Kh. Iodine deficiency in animal husbandry. Veterinariya Kubani [Veterinary medicine of the Kuban], 2014, No. 5.

4. Shantyz A.Kh. Perspektivy primeneniya yodsoderzhaschikh preparatov $v$ veterinarii [Prospects for the use of iodine-containing preparations in veterinary medicine]. Diss. abstract for DVM. Krasnodar, 2015.

5. Evglevskiy A.A., Skira V.N., Ryzhkova G.F., Mikhailova I.I. Substantiation of a new approach to the prevention of iodine deficiency and metabolism correction. Zh. Vestnik Rossiyskoy s-kh nauki [J. Bulletin of Russian Agricultural Science], 2019, No. 2, pp. 6770.

6. Li Mu, Creswell J. Eastman, Kay V. Waite, Gary Ma, Margaret R. Zacharin, Duncan J. Topliss, Philip E. Harding, John P. Walsh, Lynley C. Ward, Robin H. Mortimer, Emily J. Mackenzie, Karen Bythand Zelda Doyle. Are Australian children iodine deficient. Results of the Australian National Iodine Nutrition Study MJA, 2006, vol. 184, No. 4.

7. Jahreis G., Hausmann W., Kiesling G., France K., Leather M. Bioavailability of iodine from a normal diet rich in dairy products - results of balance studies in women. Experimental and Clinical Endocrinology and Diabetes, 2001, 109(03), pp.163-167.

8. Bader N., Möller U., Leiterer M., Franke K., Jahreis G. Iodine content in human milk and cows milk increased continuously. - Investigations in Jena/Thuringia. Submitted for publication, 2003.

9. Rasmussen L., Ovesen L., Bulow I., Jorgensen T., Knudsen N., Laurberg P., Perrild H. Dietary iodine intake and urinary iodine excretion in a Danish population: effect of geography, supplements and food choice. Lone British Journal of Nutrition, 2002, vol. 87, pp. 61-69.

10. Pearce E., Pino S., He X., Bazrafshan H.R., Lee S.L., Braverman L.E. Sources of dietary iodine: bread, cow's milk and infant formula in the Boston area. Journal of Clinical Endocrinology and Metabolism, 2004, vol. 89(7), pp. 3412-3424.

11. Jahreis G., Leather M., France K., Maichrowitz W., Schone F., Hesse. Iodine supply in schoolchildren and iodine content in milk. Kinderpraxis [Children's practice], 1999, vol. 16, pp. 172-181.

12. Sposob profilaktiki yodnoy nedostatochnosti i korrektsii metabolizma u korov [A method for preventing iodine deficiency and correcting metabolism in cows]. Patent RF, No. 2664438, 17.08.2018. 
13. Evglevskiy Al.A., Mikhaylova I.I., Evglevskaya E.P., Vanina N.V., Evglevskaya T.A. Preparations of iodine-iodinol - unknown pages, known and new qualities in its modification. Vestnik Kurskoy GSKhA [Bulletin of the Kursk State Agricultural Academy], 2015, No. 8, 194 p.

14. Mokhnach V.O., Valdman A.V., Evdokimov P.D. Yodinol v meditsine i veterinarii [Iodinol in medicine and veterinary medicine]. L., Nauka Publ., 1967, 187 p.

15. Mokhnach I.V. Blue iodine. Repressirovannaya nauka [Repressed science], 1994, vol. 2., SPb., Nauka Publ., pp.145-157.

16. Kovalenko A.L., Belyakova N.V. Succinic acid: pharmacological activity and dosage forms. Farmatsiya [Pharmacy], 2000, No. 5-6, pp. 40-42.

17. Lebedev A.F., Shvets O.M., Evglevskiy A.A., Evglevskaya E.P. et al. Development and use of preparations based on succinic acid. Veterinariya [Veterinary medicine], 2009, No. 3., pp. 48-51.

18. Ivnitskiy Yu.Yu., Golovko A.I., Safronov G.A. Yantarnaya kislota v sisteme sredstv metabolicheskoy korrektsii funktsional'nogo sostoyaniya rezistentnosti organizma [Succinic acid in the system of metabolic correction means of the functional state of the body’s resistance]. SPb., Lan Publ., 1998, 82 p.

19. Maevskiy E.I., Grishina B.V., Rozenfeld A.S. Substantiation of the use of biologically active additives based on succinic acid. Effektivnost' primeneniya BAD v razlichnykh oblastyakh meditsiny: Sb. materialov nauchn-prakticheskoy konfe-rentsii po biologicheski-aktivnym dobavkam [Efficiency of the use of dietary supplements in various fields of medicine: Collection of materials of the scientific-practical conference on biologically active additives]. M., 2000, pp. 261-265.

20. Kondrashova M.N. Terapevticheskoye deystviye yantarnoy kisloty [Therapeutic action of succinic acid]. Pushchino Publ., 1976, 234 p.

21. Evglevskiy Al.A., Mikhaylova I.I., Skira V.N., Evglevskaya E.P., Vanina N.V., Mikhaylova O.N. Complex of succinic acid with iodinol: new qualities and prospects for use. Veterinarnaya patologiya [Veterinary pathology], 2015, No. 4. pp. 37-43.

22. Evglevskiy Al.A., Skira V.N., Ryzhkova G.F., Mikhaylova I.I. Substantiation of a new approach to the prevention of iodine deficiency and metabolism correction. Zh. Vestnik Rossiyskoy s-kh nauki [J. Bulletin of Russian Agricultural Science], 2019, No. 2, pp. 6770.

23. Evglevskiy Al.A., Shvets O. M., Evglevskaya E.P., Eryzhenskaya N.F. et al. Metabolic ketoacidosis of highly productive lactating cows: causes, consequences and promising solutions. Vestnik Kurskoy gosudarstvennoy sel'skokhozyaystvennoy akademii [Bulletin of the Kursk State Agricultural Academy], 2018, No. 2, pp. 27-30.

24. Evglevskiy Al.A., Skira V.N., Evlevskaya E.P., Vanina N.V., Mikhaylova I.I. Metabolic acidosis in highly productive cows: causes, consequences, prevention. Veterinariya [Veterinary medicine], 2017, No. 5, p. 45.

25. Evglevskiy Al.A., Evlevskaya E.P., Mikhaylova I. I., Vanina N.V. Energy deficiency in high yielding cows: problems and solutions. Zh. Vestnik Rossiyskoy s-kh nauki [J. Bulletin of Russian Agricultural Science], 2017, No. 4, pp. 61-64.

26. Rozenfeld A.S. Podderzhaniye fizicheskoy rabotosposobnosti putem metabolicheskoy korrektsii atsidoza [Maintaining physical performance by metabolic correction of acidosis]. Abstract of Diss. of Doctor of Biological Sciences. Pushchino Publ., 2001, 40 p. 